\title{
Communication \\ Silica Layer Used in Sensor Fabrication from a Low-Temperature Silane-Free Procedure
}

\author{
Pei-Cheng Jiang ${ }^{1}$, Yu-Ting Chow ${ }^{1}$, Chi-Wei Chien ${ }^{2}$, Cheng-Hsun-Tony Chang ${ }^{2, *}$ and Chii-Ruey Lin ${ }^{1}$ \\ 1 Department of Mechanical Engineering, Minghsin University of Science and Technology, \\ Hsinchu 30401, Taiwan; jpc77127@must.edu.tw (P.-C.J.); tim7851@must.edu.tw (Y.-T.C.); \\ crlin@must.edu.tw (C.-R.L.) \\ 2 Department of Electronic Engineering, Minghsin University of Science and Technology, \\ Hsinchu 30401, Taiwan; B05030200@std.must.edu.tw \\ * Correspondence: chtchang@must.edu.tw
}

check for updates

Citation: Jiang, P.-C.; Chow, Y.-T.; Chien, C.-W.; Chang, C.-H.-T.; Lin, C.-R. Silica Layer Used in Sensor Fabrication from a Low-Temperature Silane-Free Procedure. Chemosensors 2021, 9, 32. https://doi.org/10.3390/ chemosensors 9020032

Academic Editors: Mateusz Smietana and Chris Blackman

Received: 19 December 2020

Accepted: 2 February 2021

Published: 4 February 2021

Publisher's Note: MDPI stays neutral with regard to jurisdictional claims in published maps and institutional affiliations.

Copyright: (c) 2021 by the authors. Licensee MDPI, Basel, Switzerland. This article is an open access article distributed under the terms and conditions of the Creative Commons Attribution (CC BY) license (https:/ / creativecommons.org/licenses/by/ $4.0 /)$.

\begin{abstract}
Silica ( $\mathrm{SiO}_{2}$, silicon dioxide - a dielectric layer commonly used in electronic devices) is widely used in many types of sensors, such as gas, molecular, and biogenic polyamines. To form silica films, core shell or an encapsulated layer, silane has been used as a precursor in recent decades. However, there are many hazards caused by using silane, such as its being extremely flammable, the explosive air, and skin and eye pain. To avoid these hazards, it is necessary to spend many resources on industrial safety design. Thus, the silica synthesized without silane gas which can be determined as a silane-free procedure presents a clean and safe solution to manufactures. In this report, we used the radio frequency $(\mathrm{rf}=13.56 \mathrm{MHz}$ ) plasma-enhanced chemical vapor deposition technique (PECVD) to form a silica layer at room temperature. The silica layer is formed in hydrogen-based plasma at room temperature and silane gas is not used in this process. The substrate temperature dominates the silica formation, but the distance between the substrate and electrode $\left(D_{\mathrm{STE}}\right)$ and the methane additive can enhance the formation of a silica layer on the Si wafer. This silane-free procedure, at room temperature, is not only safer and friendlier to the environment but is also useful in the fabrication of many types of sensors.
\end{abstract}

Keywords: silica; silane-free; sensors; rf-PECVD

\section{Introduction}

The most popular application for silica is the dielectric layer [1] and spacer [2] in the processing of integral circuits. Furthermore, there have been some novel applications in biotechnology [3-5], photoelectric technique [6], organic photoresists [7-10] and sensors [11-14]. Silica is especially widely used in many types of sensors, such as gas, molecular and biogenic polyamines [7-14]. For example, the silica functionalization process is used to immobilize a variety of biomolecules, including glucose oxidase, horseradish peroxide, metallothionein, and DNA molecules [11]. A solid-state electrochemiluminescence sensor based on $\mathrm{Ru}(\mathrm{bpy})^{32+}$-encapsulated silica nanoparticles, covalently immobilized on a screen-printed carbon electrode, has been developed and characterized [14]. Among those novel applications, the processing temperature plays a crucial role in the final production yield for applications, not only in the processing of integral circuits, but also in biotechnology. The method used to process silica is the direct exposure of oxygen to a Si wafer with a processing temperature from 900 to 1200 degrees Celsius $\left({ }^{\circ} \mathrm{C}\right)$ [15]. In the 2000s, silane was announced as the main material used to fulfill the low-temperature silica deposition, with the technology of plasma-enhanced chemical vapor deposition (PECVD) [16,17]. In addition, to achieve fewer defects and higher uniformity, the processing temperature is pushed to a limit of from around 50 to $200{ }^{\circ} \mathrm{C}$ for silica deposition by the low-temperature or plasma-enhanced atomic layer deposition (ALD) technique [18-21]. However, silane has many dangers due to its flammable, explosive properties. Therefore, the environment is 
confirmed to be clean and safe when silane is not used in the fabricating procedure. In this report, we offer a silane-free procedure for depositing silica on a 12" silicon wafer at room temperature in a hydrogen-based plasma by PECVD technique. The substrate temperature dominates the silica formation, but the $D_{\mathrm{STE}}$ and methane additive can both enhance the formation of silica layer on the $\mathrm{Si}$ wafer. This silane-free procedure at room temperature is not only safer and friendlier to the environment, but also useful in the fabrication of many types of sensors. We may produce a chemo-sensor by utilizing silica, and the schematic plot of the sensor head is shown in Figure 1. First, the silica films are deposited on top of the $\mathrm{Si}$ substrate as a gate between the source and drain, which is produced by an ion plant. The shape and alignment of the gate, source and drain are simply, schematically shown in Figure 1. On top of the silica gate, a blocking sheet is deposited to absorb the specific kind of aptamer. Therefore, the target material will be successful in sensing. To summarize, the hydrogen-based plasma by PECVD technique can be perfectly controlled and is able to synthesize the silica layer on the Si substrate at room temperature. Thus, the silica layer can be widely used in many types of sensors, such as gas, molecular and biogenic polyamines.

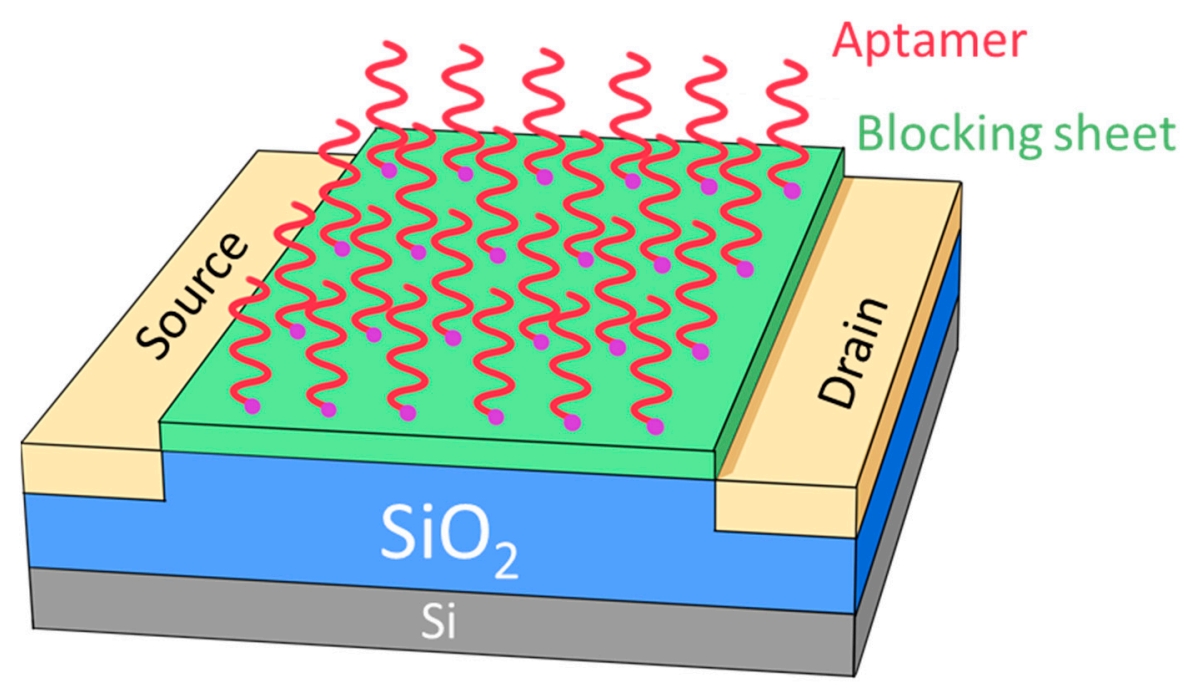

Figure 1. The schematic plot for sensors in universal construction contains source and drain electrode, gate $\left(\mathrm{SiO}_{2}\right.$ layer), base ( $\mathrm{Si}$ substrate), blocking sheet and aptamers.

\section{Materials and Methods}

A 12-inch Si (100) wafer is used as the substrate of silica deposition. The contaminations and native silica on substrate surface are cleaned by the Radio Corporation of America (RCA) cleaning process. After the cleaning procedure, the wafer is loaded to the chamber of ULVAC-PECVD with $13.56 \mathrm{MHz}$ radio frequency signal. The electrode is suitable for 12 " wafer production with a $300 \times 400 \mathrm{~mm}$ rectangle showerhead, which offers plenty of gas inlets to deliver the process gas to the substrate surface, with a methane, oxygen and hydrogen gas of $99.999 \%$ purity. The mixture for $\mathrm{CH}_{4}$ and oxygen of $500 \mathrm{ppm}$ is simultaneously delivered in the processing chamber with hydrogen with a flow rate of $37: 100 \mathrm{sccm}$. At this moment, the concentration of $\mathrm{CH}_{4}$ can be determined as $27 \%$. The deposition experiments of silica are carried out under the reaction pressure of $133 \mathrm{~Pa}$ and a distance between substrate and electrode $\left(D_{\mathrm{STE}}\right)$ of $40 \mathrm{~mm}$, combined with an rf-power of $250 \mathrm{~W}$. This processing recipe design was mainly chosen to use the hydrogen plasma as a background in order to form silica. The methane molecular is the most similar material in terms of atom composition, and is used to replace silane in the plasma conditions for PECVD. Although there are no Si atoms in the methane molecular, the methane molecular still supplies considerable energy to the oxygen and $\mathrm{Si}$ wafer to synthesize the silica layer at room temperature. The extremely low flux of oxygen may limit the synthesizing rate for silica; the lower synthesizing rate always can obtain a much more uniform layer and fewer defects $[22,23]$. The large flux in hydrogen is used to etch carbon atoms and silica 
clusters [24-26]. In this report, we especially use the hydrogen to etch and deposit silica at the same time, which may enhance the uniformity and reduce the defects. This idea is inspired by the self-ion sputtering technique [27-29]. Surface morphologies, cross-sections and energy-dispersive X-ray analysis of the deposited films are examined with JEOL scanning electron microscopy (SEM). Atomic force microscopy (AFM) is also employed to investigate the surface morphology of silica films. The thickness of the deposited films can be calculated by the fitting data from ellipsometry. The incident beam of ellipsometry measurement is set up from 45 to 60 degrees ( 5 degrees/measurement). The result is well fitted for all data at the same model in a series measurement. The light source, Quartz Tungsten Halogen (QTH) lamp is within a reliable scanning range from visible to nearinfrared (NIR), which is suitable for measuring the silica layer. The refraction index $\mathrm{n}$ and dielectric constant $\mathrm{k}$ can also be calculated by the analysis of ellipsometry measurement. In Figure 2a-c, the ellipsometry results for native oxide, deposition time of 20 and $40 \mathrm{~min}$, are shown, respectively. The scanning angle for Figure $2 a-c$ is between 45 and 60 degrees. In order to get the thickness of the silica films for Figure 2a-c, the ellipsometry results should be fitted by the commercial software. Because the light source for the ellipsometry measurements is sensitive for the wavelength between 350 and $1000 \mathrm{~nm}$, the fitting range is chosen to be between 350 and $1000 \mathrm{~nm}$. After the analysis, the ellipsometry results in Figure $2 \mathrm{a}-\mathrm{c}$ are all well-fitted, indicating that the silica thin films deposited by this recipe are perfectly fitted to be a uniform silica layer on the $\mathrm{Si}$ wafer. This is a common and standard analysis using ellipsometry results to confirm the thickness of silica thin films $[30,31]$.

\section{(a)}

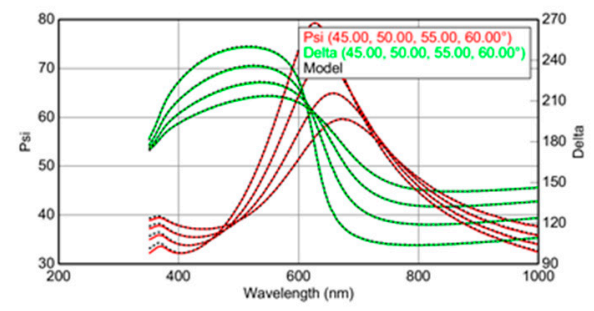

(b)

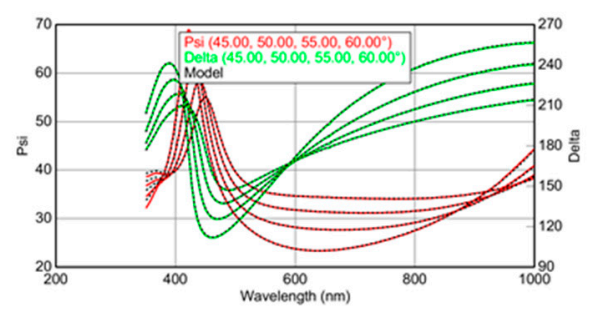

(c)

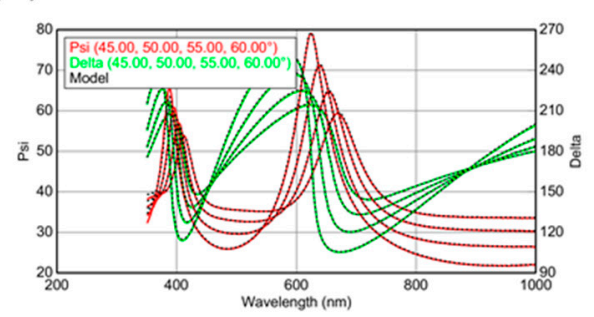

Figure 2. The ellipsometry results for (a) native oxide and silicon dioxide with deposition times of (b) 20 and (c) 40 min are measured and fitted by the EASE program from J. A. Woollam Co., Inc., Lincoln, NE, USA. 


\section{Results and Discussion}

\subsection{Optical and SEM Measurements for the Silica Layer}

The systematical data are shown in Figure 3a. The stable linear increase in the thickness of silica can be observed as the deposition time increases, indicating that the deposition rate is $3.5 \mathrm{~nm} / \mathrm{min}$. Furthermore, the inset in Figure 3a simultaneously shows the high uniformity of thin films and the thickness of $210 \mathrm{~nm}$, which coincides with the results from ellipsometry. The systematical research on different substrate temperatures, $\mathrm{CH}_{4}$ concentration and $D_{\mathrm{STE}}$ are carried out under the standard of this recipe in order to find out the dominant condition and mechanism of the silica deposition. In Figure $3 b$, the thickness of silica thin film decreases from 210 to $4 \mathrm{~nm}$ as the substrate temperature increases from room temperature to $150{ }^{\circ} \mathrm{C}$. The thickness of silica thin film remains from 3 to $4 \mathrm{~nm}$, which coincides with the native oxide of the silicon wafer. The inset in Figure $3 \mathrm{~b}$ is the energy-dispersive X-ray spectroscopy (EDS) and Raman spectrum of the $\mathrm{SiO}_{2}$ layer, indicating that it is a pure silica film without carbon atoms, with the feeding of methane gas. This result implies that a substrate is over $150{ }^{\circ} \mathrm{C}$ is not beneficial for silica deposition. This phenomenon can be attributed to the thermal disturbance and hydrogen plasma etching between 150 and $300{ }^{\circ} \mathrm{C}$. The thermal disturbance is not beneficial for the oxide adsorption and chemical combination on the substrate surface, which has been reported in the literature as different material interfaces [32-34]. In addition, the hydrogen plasma can etch the silica layer and carbon atoms with a higher temperature [24-26]. From the results mentioned above, $150{ }^{\circ} \mathrm{C}$ is the transition point for the deposition of silica under the influence of substrate temperature. Therefore, the comparison of the experimental results with a substrate temperature of 100 and $200{ }^{\circ} \mathrm{C}$ is focused on in the following research.

(a)

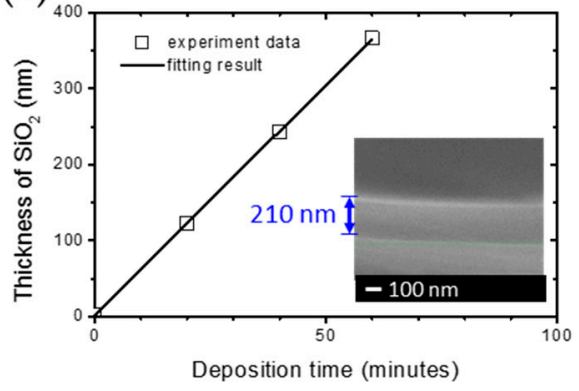

(b)

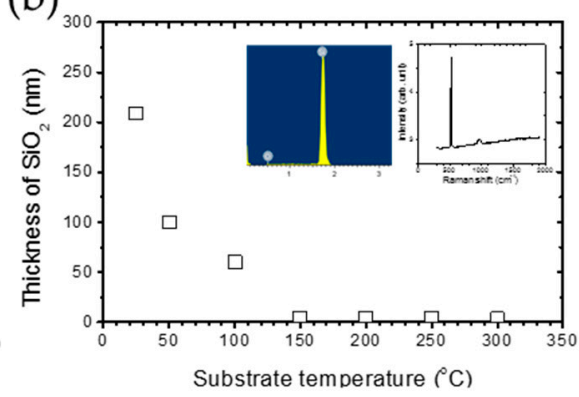

Figure 3. (a) The thickness of $\mathrm{SiO}_{2}$ from ellipsometry results and fitting by a linear behavior in deposition time. The inset plot is the cross-section SEM image for a deposition time of $60 \mathrm{~min}$. (b) The relationship between the thickness of the $\mathrm{SiO}_{2}$ layer and substrate temperature from room temperature to $300^{\circ} \mathrm{C}$ with $27 \% \mathrm{CH}_{4}, 500 \mathrm{ppm} \mathrm{O}_{2}, D_{\mathrm{STE}}=40 \mathrm{~mm}$.

\subsection{Methane Additive Enhanced the Silica Layer}

The effect of $D_{\text {STE }}$ on silica deposition is shown in Figure 4a. At a substrate temperature of $100{ }^{\circ} \mathrm{C}$, as $D_{\mathrm{STE}}$ increases from 10 to $40 \mathrm{~mm}$, and the thickness of silica thin film reduces from 250 to $50 \mathrm{~nm}$. Most importantly, a linear relationship can be observed when $D_{\text {STE }}$ is between 10 and $30 \mathrm{~mm}$. This result indicates that it can be discussed by simplifying the model for the parallel plate capacitor [35]. The $D_{\mathrm{STE}}$ can be considered as the capacitor distance, and the capacity (C) can be expressed by Equation (1):

$$
C \approx \frac{\varepsilon A}{D_{\mathrm{STE}}} \text {, when } A \gg\left(D_{\mathrm{STE}}\right)^{2}
$$

where $A$ is the area of the capacitor plates and $\varepsilon$ is the permittivity of dielectric. When the plasma is stable, $A$ and $\varepsilon$ are assumed to be constants. Therefore, the capacity is proportional to $1 / D_{\text {STE }}$. Compared with the experimental results, the deposition rate, being proportional to capacity and $1 / D_{\mathrm{STE}}$, can be concluded. Therefore, the capacity is higher with a smaller $D_{\mathrm{STE}}$, resulting in its owning sufficient energy to help the deposition of silica thin film. 
However, when $D_{\text {STE }}$ is longer than $30 \mathrm{~mm}$, it deviates from the prediction of the parallel plate capacitor model, which can be attributed to the interval being too big to let the gas-flow fill the whole capacitor. The results in the thickness of silica deposition being lower than predicted. Nevertheless, when the substrate temperature is $200^{\circ} \mathrm{C}$, the silica cannot successfully be deposited on a silicon wafer by tuning $D_{\mathrm{STE}}$.

(a)

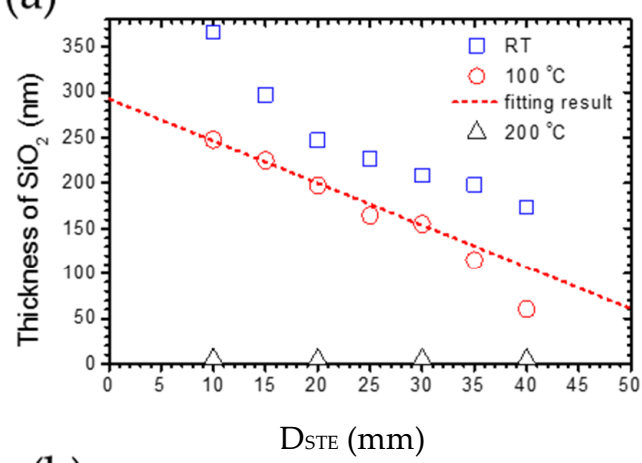

(b)

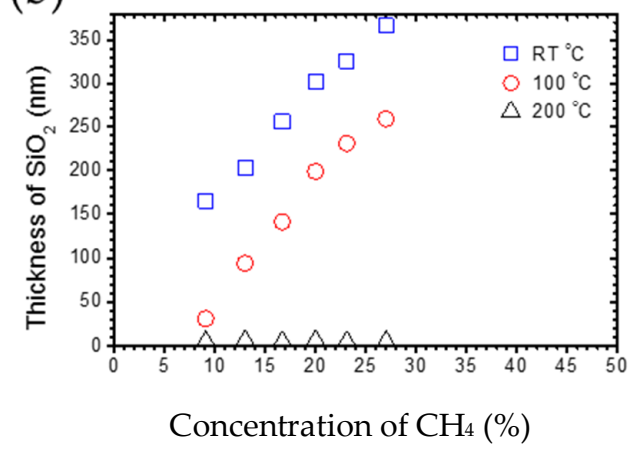

(c)

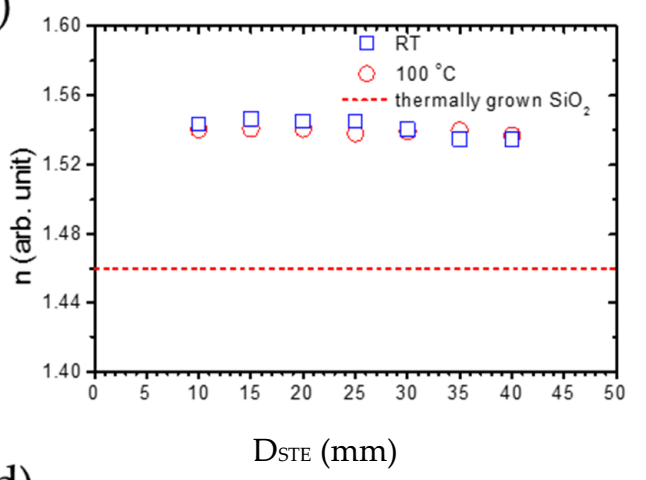

(d)

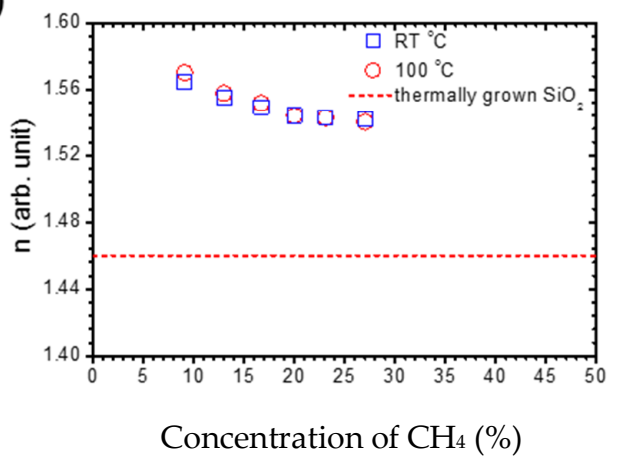

Figure 4. The relationship between the thickness of the $\mathrm{SiO}_{2}$ layer and (a) $D_{\text {STE }}$ from 10 to $40 \mathrm{~mm}$ with $27 \% \mathrm{CH} 4,500 \mathrm{ppm} \mathrm{O}_{2}$ at 100 and $200{ }^{\circ} \mathrm{C}$, and (b) the concentration of $\mathrm{CH}_{4}$ from 9 to $27 \%$ with $500 \mathrm{ppm} \mathrm{O}_{2}, D_{\mathrm{STE}}=10 \mathrm{~mm}$ at room temperature, 100 and $200^{\circ} \mathrm{C}$. The deposition time is an hour. $(\mathbf{c}, \mathbf{d})$ are the respective refraction indexes $\mathrm{n}$ for $(\mathbf{a}, \mathbf{b})$.

On the other hand, the thickness of the silica thin film versus concentration of $\mathrm{CH}_{4}$ is shown in Figure $4 \mathrm{~b}$ with oxygen levels at $500 \mathrm{ppm}$ and $D_{\text {STE }}$ at $10 \mathrm{~mm}$. At a substrate temperature of $100^{\circ} \mathrm{C}$, the thickness of silica increases significantly when the concentration of $\mathrm{CH}_{4}$ increases. The reason for this is that the increased concentration of $\mathrm{CH}_{4}$ can significantly enhance the plasma density [36], resulting in the enhancement of chemical reactions between $\mathrm{Si}$ and $\mathrm{O}$ atoms. However, when the substrate temperature is $200{ }^{\circ} \mathrm{C}$, the silica cannot be successfully deposited on a silicon wafer by a tuning concentration of $\mathrm{CH}_{4}$. Furthermore, to discuss the quality of silica films, the refraction index $\mathrm{n}$ is necessary. The refraction index $\mathrm{n}$ for the light source with a wavelength of $632.8 \mathrm{~nm}$ can be calculated from the analysis of ellipsometry results. As the silica films are successfully deposited at the deposition temperature of room temperature and $100^{\circ} \mathrm{C}$, we will discuss only the $\mathrm{n}$ for series at a deposition temperature of room temperature and $100{ }^{\circ} \mathrm{C}$. The effect of $D_{\text {STE }}$ on the $n$ of silica films is shown in Figure 4c. When the $D_{\text {STE }}$ increases from 10 to $40 \mathrm{~nm}, \mathrm{n}$ for silica films deposited at room temperature and $100{ }^{\circ} \mathrm{C}$ is almost consistent at 1.54. The extinction coefficient is almost zero. This implies that the quality of silica films is not influenced by $D_{\mathrm{STE}}$. On the other hand, the refraction index with a different concentration of $\mathrm{CH}_{4}$ is shown in Figure $4 \mathrm{~d}$. With the increasing concentration of $\mathrm{CH}_{4}$, $\mathrm{n}$ slightly decreases from 1.57 to 1.54 for silica films deposited at room temperature and $100{ }^{\circ} \mathrm{C}$. The extinction coefficient is almost zero. The dash line is the refraction index for the thermally grown silica film, whose value is 1.46 [37]. The decrease in $\mathrm{n}$ can be attributed to 
the increase in the pinholes, because $\mathrm{n}$ for pure silica films is 1.6. In summary, the substrate temperature dominates the silica formation, but the $D_{\mathrm{STE}}$ and methane additive can both enhance the formation of a silica layer on the Si wafer.

\subsection{Uniformity Measurements for the Silica Layer}

Therefore, that recipe is adopted to the uniformity research of large-area deposition on an industrial-size 12" Si wafer, which is shown in Figure 5. In Figure 5a, the thickness of silica remains at 360 and $250 \mathrm{~nm}$ for the deposition temperature of RT and $100{ }^{\circ} \mathrm{C}$, respectively, when the distance to the center of the silicon wafer increases from 0 to $6^{\prime \prime}$. After calculating the uniformity of the silica thin film, which can be defined by the ratio between the thickness of silica thin film at $x^{\prime \prime}$ and the center of silicon wafer, we can see that the uniformity remains at 1.0, which is shown in Figure 5b. In Figure 5c, the refraction index of silica remains near 1.54 for a deposition temperature of room temperature and $100{ }^{\circ} \mathrm{C}$, but the refraction index of silica deposited at room temperature is a little bigger than the silica deposited at $100{ }^{\circ} \mathrm{C}$. The extinction coefficient is almost zero. In Figure $5 \mathrm{~d}$, the dielectric constants of silica are consistent at 2.39 and 2.37 for deposition temperatures of room temperature and $100{ }^{\circ} \mathrm{C}$, respectively. The dashed line is the refraction index for thermally grown silica film, whose value is 2.2 [38].

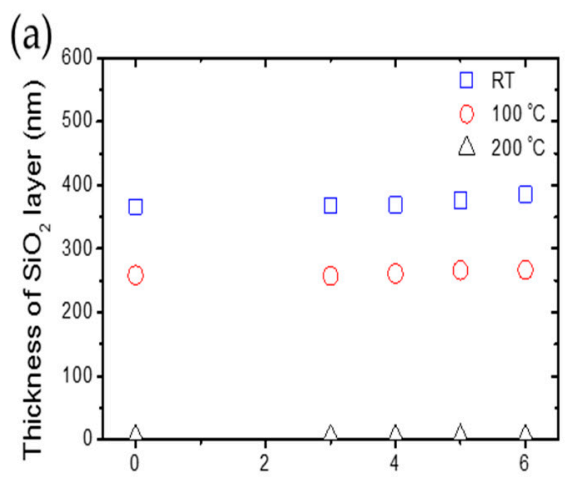

(b)

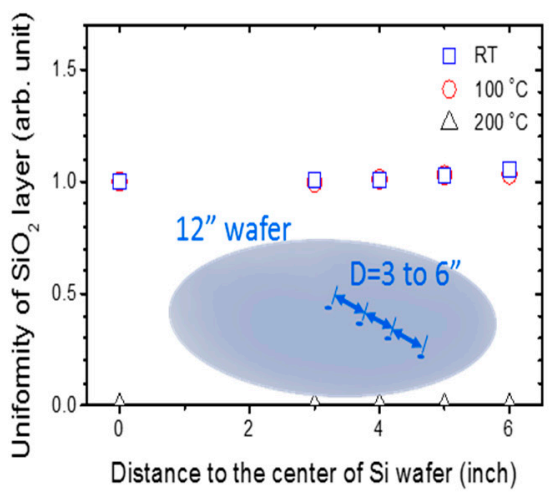

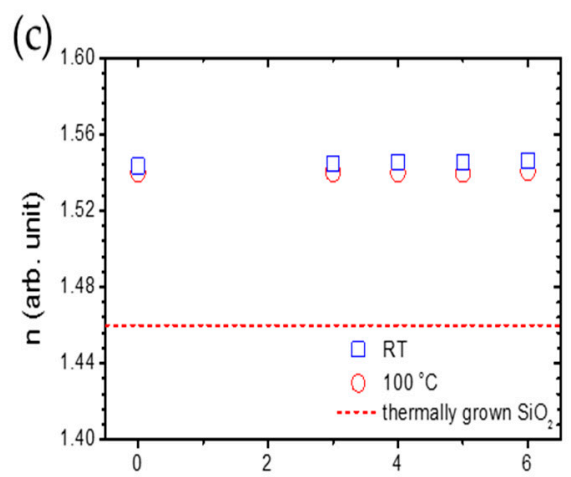

(d)

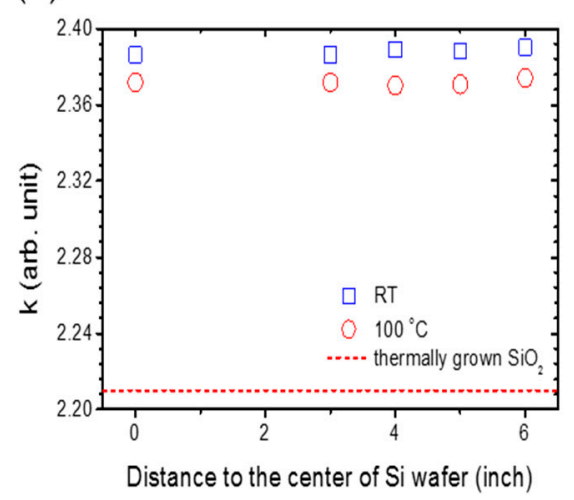

Figure 5. The relationship between (a) the thickness of the $\mathrm{SiO}_{2}$ layer, (b) the uniformity of the $\mathrm{SiO}_{2}$ layer, (c) refraction index $\mathrm{n},(\mathrm{d})$ dielectric constant $\mathrm{k}$ and the distance to the center of the Si wafer with a concentration of $27 \% \mathrm{CH}_{4}, 500 \mathrm{ppm} \mathrm{O}_{2}, \mathrm{D}_{\mathrm{STE}}=10 \mathrm{~mm}$ at room temperature, 100 and $200{ }^{\circ} \mathrm{C}$. The deposition time is an hour.

The AFM images for silica deposition at room temperature and $100{ }^{\circ} \mathrm{C}$ at the center of the $\mathrm{Si}$ wafer are shown in Figure 6a,b respectively. The roughness for silica films deposited at room temperature is steady at $0.32 \mathrm{~nm}$ for any position at the 12 " Si wafer, while the roughness for silica films deposited at $100{ }^{\circ} \mathrm{C}$ is steady at $1.02 \mathrm{~nm}$. The red circle marks in Figure $6 \mathrm{a}, \mathrm{b}$ represent the locations of pinholes in the silica films, and the average diameter and depth of pinholes are 100 and $2 \mathrm{~nm}$, respectively. This implies that the formations of 
silica thin film in this recipe is not influenced by the distance to the center of the $\mathrm{Si}$ wafer when the wafer is smaller than 12 ". Therefore, a large-area silica deposition can be fulfilled from this recipe.
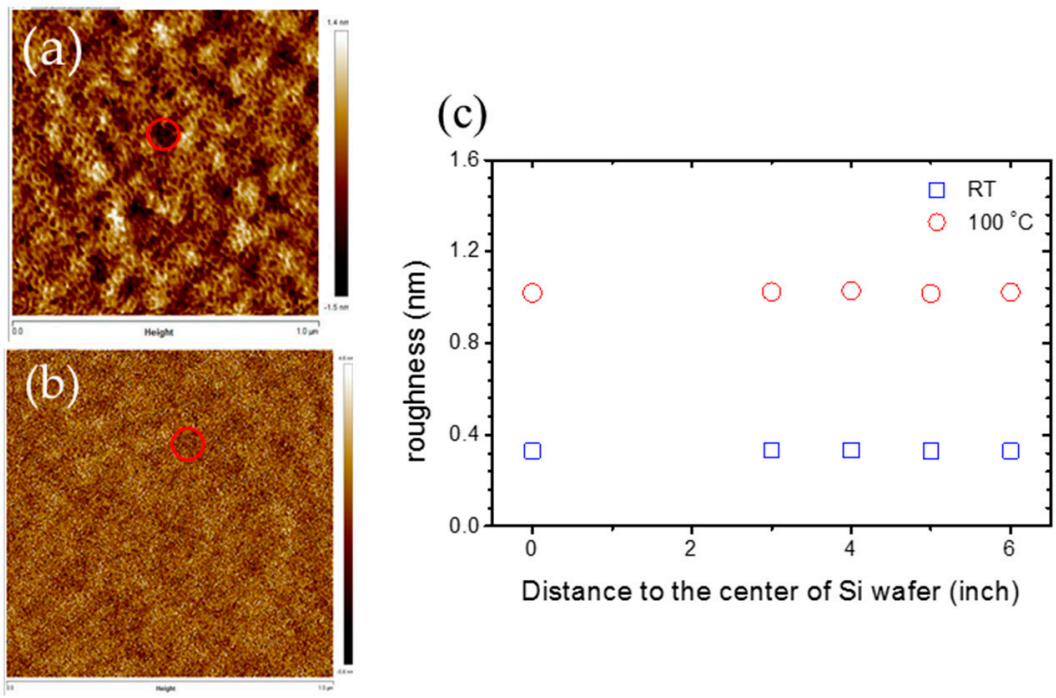

Figure 6. The atomic force microscopy (AFM) images for the $\mathrm{SiO}_{2}$ layer deposited at (a) room temperature and (b) $100{ }^{\circ} \mathrm{C}$ at the center of the Si wafer; (c) is the roughness of $\mathrm{k}$ and the distance to the center of the $\mathrm{Si}$ wafer with a concentration of $27 \% \mathrm{CH}_{4}, 500 \mathrm{ppm} \mathrm{O}_{2}, D_{\mathrm{STE}}=10 \mathrm{~mm}$. The deposition time is an hour.

\section{Conclusions}

We successfully use the rf-PECVD to form a silica layer on the 12 " Si wafer at room temperature in a hydrogen-based plasma. The substrate temperature dominates the silica formation, but the $D_{\mathrm{STE}}$ and methane additive can both enhance the formation of the silica layer on the $\mathrm{Si}$ wafer. The EDS and Raman spectrum of the $\mathrm{SiO}_{2}$ layer indicate that this is a pure silica film, without carbon atoms and with the feeding of methane gas. The refraction index and dielectric constant analysis imply that the silica film from this recipe is better than the thermally grown silica. Furthermore, this silane-free procedure at room temperature is not only safer and friendlier to the environment but is also useful in the fabrication of many types of sensors, such as gas, molecular and biogenic polyamines.

Author Contributions: Conceptualization, C.-H.-T.C. and C.-R.L.; data curation, P.-C.J., Y.-T.C. and C.-W.C.; formal analysis, P.-C.J., Y.-T.C. and C.-W.C.; investigation, P.-C.J., Y.-T.C. and C.-W.C.; methodology, C.-H.-T.C.; supervision, C.-H.-T.C. and C.-R.L.; validation, P.-C.J. and Y.-T.C.; writingoriginal draft, P.-C.J. and Y.-T.C.; writing-review and editing, C.-H.-T.C. All authors have read and agreed to the published version of the manuscript.

Funding: This research was funded by Contract Nos. MOST 108-2622-E-159-003-CC2, MOST 1092112-M-159-001-MY2, and MOST 109-2221-E-159-001.

Institutional Review Board Statement: Not applicable.

Informed Consent Statement: Not applicable.

Data Availability Statement: Data sharing not applicable.

Acknowledgments: The authors wish to acknowledge support from Ministry of Science and Technology of Republic of China under Contract Nos. MOST 108-2622-E-159-003-CC2, MOST 109-2112M-159-001-MY2, and MOST 109-2221-E-159-001. We also would like to acknowledge Ulvac Taiwan Inc. for providing their Cluster-type PE-CVD System: CME-400.

Conflicts of Interest: The authors declare no conflict of interest. 


\section{References}

1. Wu, X.; Xing, Y.; Zeng, K.; Huber, K.; Zhao, J.X. Study of Fluorescence Quenching Ability of Graphene Oxide with a Layer of Rigid and Tunable Silica Spacer. Langmuir 2017, 34, 603-611. [CrossRef]

2. Liu, L.; Lv, F.; Li, P.; Ding, L.; Tong, W.; Chu, P.K.; Zhang, Y. Preparation of ultra-low dielectric constant silica/polyimide nanofiber membranes by electrospinning. Compos. Part A: Appl. Sci. Manuf. 2016, 84, 292-298. [CrossRef]

3. Shang, Y.; Li, N.; Liu, S.; Wang, L.; Wang, Z.; Zhang, Z.; Ding, B. Site-Specific Synthesis of Silica Nanostructures on DNA Origami Templates. Adv. Mater. 2020, 32, e2000294. [CrossRef]

4. Nguyen, T.L.; Choi, Y.; Kim, J. Mesoporous Silica as a Versatile Platform for Cancer Immunotherapy. Adv. Mater. 2019, 31, 1803953-1-1803953-7. [CrossRef] [PubMed]

5. Martino, N.; Kwok, S.J.J.; Liapis, A.C.; Forward, S.; Jang, H.; Kim, H.-M.; Wu, S.J.; Wu, J.; Dannenberg, P.H.; Jang, S.-J.; et al. Wavelength-encoded laser particles for massively multiplexed cell tagging. Nat. Photonics. 2019, 13, 720-727. [CrossRef] [PubMed]

6. Ilic, O.; Atwater, H.A. Self-stabilizing photonic levitation and propulsion of nanostructured macroscopic objects. Nat. Photonics. 2019, 13, 289-295. [CrossRef]

7. Pasini, D.; Takeuchi, D. Cyclopolymerizations: Synthetic Tools for the Precision Synthesis of Macromolecular Architectures. Chem. Rev. 2018, 118, 8983-9057. [CrossRef]

8. Fang, G.; Cao, H.; Cao, L.; Duan, X. Femtosecond Laser Direct Writing of 3D Silica-like Microstructure from Hybrid Epoxy Cyclohexyl POSS. Adv. Mater. Technol. 2017, 3, 1700271. [CrossRef]

9. Klopp, J.M.; Pasini, D.; Byers, J.D.; Willson, C.G.; Fréchet, J.M.J. Microlithographic Assessment of a Novel Family of Transparent and Etch-Resistant Chemically Amplified 193-nm Resists Based on Cyclopolymers. Chem. Mater. 2001, 13, 4147-4153. [CrossRef]

10. Lee, C.-K.; Don, T.-M.; Lai, W.-C.; Chen, C.-C.; Lin, D.-J.; Cheng, L.-P. Preparation and properties of nano-silica modified negative acrylate photoresist. Thin Solid Films 2008, 516, 8399-8407. [CrossRef]

11. Sciuto, E.L.; Bongiorno, C.; Scandurra, A.; Petralia, S.; Cosentino, T.; Conoci, S.; Sinatra, F.; Libertino, S. Functionalization of Bulk $\mathrm{SiO}_{2}$ Surface with Biomolecules for Sensing Applications: Structural and Functional Characterizations. Chemosensors 2018, 6, 59. [CrossRef]

12. Zahmouli, N.; Marini, S.; Guediri, M.; Ben Mansour, N.; Hjiri, M.; El Mir, L.; Espro, C.; Neri, G.; Leonardi, S.G. Nanostructured Nickel on Porous Carbon-Silica Matrix as an Efficient Electrocatalytic Material for a Non-Enzymatic Glucose Sensor. Chemosensors 2018, 6, 54. [CrossRef]

13. Li, Z. Nanoporous Silica-Dye Microspheres for Enhanced Colorimetric Detection of Cyclohexanone. Chemosensors 2018, 6, 34. [CrossRef]

14. Spehar-Délèze, A.-M.; Almadaghi, S.; O'Sullivan, C.K. Development of Solid-State Electrochemiluminescence(ECL) Sensor Based on $\mathrm{Ru}(\mathrm{bpy})_{3}{ }^{2+}$-Encapsulated Silica Nanoparticles for the Detection of Biogenic Polyamines. Chemosensors 2015, 3, 178-189. [CrossRef]

15. Osburn, C.M.; Ormond, D.W. Dielectric Breakdown in Silica Films on Silicon: II Influence of Processing and Materials. J. Electrochem. Soc. 1972, 119, 597-603. [CrossRef]

16. Lee, J.W.; Mackenzie, K.D.; Johnson, D.; Sasserath, J.N.; Pearton, S.J.; Ren, F. Low Temperature Silicon Nitride and Silica Film Processing by Inductively Coupled Plasma Chemical Vapor Deposition. J. Electrochem. Soc. 2000, 147, 1481-1486. [CrossRef]

17. Rodr'iguez, J.A.; Llobera, A.; Domínguez, C. Evolution of the mechanical stress on PECVD silicon oxide films under thermal processing. J. Mater. Sci. Lett. 2000, 19, 1399-1401. [CrossRef]

18. Sheng, J. Performance and Stability Enhancement of $\mathrm{In}-\mathrm{Sn}-\mathrm{Zn}-\mathrm{O}$ TFTs Using $\mathrm{SiO}_{2}$ Gate Dielectrics Grown by Low Temperature Atomic Layer Deposition. ACS Appl. Mater. Interfaces 2017, 9, 42928-42934. [CrossRef]

19. Kim, D.H.; Lee, H.J.; Jeong, H.; Shong, B.; Kim, W.-H.; Park, T.J. Thermal Atomic Layer Deposition of Device-Quality SiO2 Thin Films under $100{ }^{\circ} \mathrm{C}$ Using an Aminodisilane Precursor. Chem. Mater. 2019, 31, 5502-5508. [CrossRef]

20. Hiller, D.; Zierold, R.; Bachmann, J.; Alexe, M.; Yang, Y.; Gerlach, J.W.; Stesmans, A.; Jivanescu, M.; Müller, U.; Vogt, J.B.; et al. Low temperature silicon dioxide by thermal atomic layer deposition: Investigation of material properties. J. Appl. Phys. 2010, 107, 064314. [CrossRef]

21. Lee, Y.-S.; Choi, D.-W.; Shong, B.; Oh, S.; Park, J.-S. Low temperature atomic layer deposition of SiO2 thin films using diisopropylaminosilane and ozone. Ceram. Int. 2017, 43, 2095-2099. [CrossRef]

22. Johnson, R.W.; Hultqvist, A.; Bent, S.F. A brief review of atomic layer deposition: From fundamentals to applications. Mater. Today 2014, 17, 236-246. [CrossRef]

23. Herman, M.A. Molecular Beam Epitaxy: Fundamentals and Current Status; Springer: Berlin Heidelberg, Germany, 2012.

24. Behr, M.J.; Gaulding, E.A.; Mkhoyan, K.A.; Aydil, E.S. Hydrogen etching and cutting of multiwall carbon nanotubes. J. Vac. Sci. Technol. B 2010, 28, 1187-1194. [CrossRef]

25. Chang, R.P.H. Hydrogen etching of Semconductors and Oxides. U.S. Patent 4,361,461, 30 November 1982.

26. Zaitsu, M.; Kobayashi, N.; Kobayashi, A.; Hori, M.; Tsutsumi, T. Method of Atomic Layer Etching Using Hydrogen Plasma. U.S. Patent No US 10,504,742 B2, 10 October 2019.

27. Sakamoto, Y.; Kamada, K.; Hamaguchi, J.; Sano, A.; Numata, Y.; Kodaira, S.; Suu, K. Improved Step Coverage of Cu Seed Layers by Magnetic-Field-Assisted Ionized Sputtering. Jpn. J. Appl. Phys. 2011, 50, 05EA03. [CrossRef]

28. Ding, P.; Xu, Z.; Mosely, R.; Rengarajan, S.; Maity, N.; Carl, D.; Forster, J. Self-Ionized and Inductively Coupled Plasma for Sputtering and Resputtering. U.S. Patent No US 8,696,875 B2, 15 April 2014. 
29. Ding, P.; Xu, Z.; Mosely, R.; Rengarajan, S.; Maity, N.; Carl, D.; Forster, J. Self-Ionized and Inductively Coupled Plasma for Sputtering and Resputtering. U.S. Patent No US 2008/0110747 A1, 15 May 2008.

30. Gong, J.; Dai, R.; Wang, Z.; Zhang, C.; Yuan, X.; Zhang, Z. Temperature dependent optical constants for Silica film on Si substrate by ellipsometry. Mater. Res. Express 2017, 4, 085005. [CrossRef]

31. Battie, Y.; En Naciri, A.; Chaoui, N.; Le Gall, Y.; Muller, D.; Carrada, M.; Mathiot, D. Plasmonic properties of implanted Ag nanoparticles in Silica thin layer by spectroscopic ellipsometry. J. Appl. Phys. 2017, 122, 085308. [CrossRef]

32. Bagsican, F.R.; Winchester, A.; Ghosh, S.; Zhang, X.; Ma, L.; Wang, M.; Murakami, H.; Talapatra, S.; Vajtai, R.; Ajayan, P.M.; et al. Adsorption energy of oxygen molecules on graphene and two dimensional tungsten disulfide. Sci. Rep. 2017, 7, 1774. [CrossRef] [PubMed]

33. Yu, W.-Y.; Zhang, L.; Mullen, G.M.; Evans, E.J.; Henkelman, G.; Mullins, C.B. Effect of annealing in oxygen on alloy structures of Pd-Au bimetallic model catalysts. Phys. Chem. Chem. Phys. 2015, 17, 20588-20596. [CrossRef]

34. Desai, S.C.; Hewaparakrama, K.P.; Jayasinghe, C.; Mast, D.; Pradhan, B.K.; Sumanasekera, G.U. Desorption kinetics of oxygen in plasma treated SWNTs by in situ thermoelectric power measurements. Nanotechnology 2008, 18, 095507. [CrossRef]

35. Griffiths, D.J. Introduction to Electrodynamics; Pearson: Boston, MA, USA, 2013.

36. Griffiths, D.J.; Inglefield, C. Plasma Physics; Springer: Berlin/Heidelberg, Germany, 2010.

37. Pliskin, W.A.; Esch, R.P. Refractive Index of SiO2 Films Grown on Silicon. J. Appl. Phys. 1965, 36, 2011. [CrossRef]

38. Osburn, C.M.; Weitzman, E.J. Electrical Conduction and Dielectric Breakdown in Silicon Dioxide Films on Silicon. J. Electrochem. Soc. 1972, 119, 603. [CrossRef] 